\title{
WHJILK
}

\section{Wind System Value Analysis for Electric Utilities: A Comparison of Four Methods}

\author{
Jim Harper \\ David Percival \\ Theresa Flaim
}

November 1981

Prepared under Task No. 1066.25

WPA No. 171A-81

Fifth Biannual Wind Workshop and Conference 5-7 October 1981
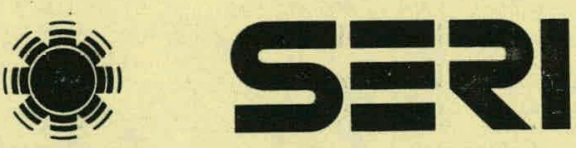

Solar Energy Research Institute

A Division of Midwest Research Institute

1617 Cole Boulevard

Golden, Colorado 80401

Prepared for the

U.S. Department of Energy

Contract No. EG-77-C-01-4042 


\section{DISCLAIMER}

This report was prepared as an account of work sponsored by an agency of the United States Government. Neither the United States Government nor any agency Thereof, nor any of their employees, makes any warranty, express or implied, or assumes any legal liability or responsibility for the accuracy, completeness, or usefulness of any information, apparatus, product, or process disclosed, or represents that its use would not infringe privately owned rights. Reference herein to any specific commercial product, process, or service by trade name, trademark, manufacturer, or otherwise does not necessarily constitute or imply its endorsement, recommendation, or favoring by the United States Government or any agency thereof. The views and opinions of authors expressed herein do not necessarily state or reflect those of the United States Government or any agency thereof. 


\section{DISCLAIMER}

Portions of this document may be illegible in electronic image products. Images are produced from the best available original document. 


\section{NOTICE}

This report was prepared as an account of work sponsored by an agency of the United States Government. Neither the United States nor any agency thereof, nor any of their employees, makes any warranty, expressed or implied, or assumes any legal liability or responsibility for any third party's use or the results of such use of any information, apparatus, product, or process disclosed in this report, or represents that its use by such third party would not infringe privately owned rights. 


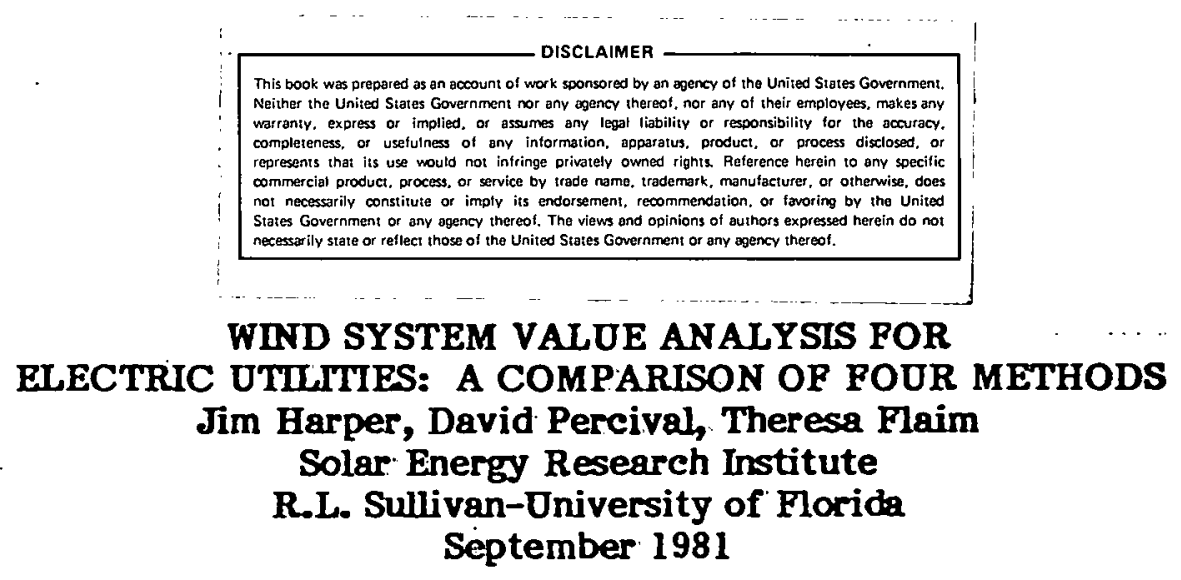

\begin{abstract}
There have been several studies of how much Wind Energy Conversion Systems (WECS) are worth to electric utilities. When attempting to compare the different results of these studies, questions arose concerning the effect of the different methodologies and models on the determined WECS values. This paper will report on the only known effort that used more than a single methodology for the value analysis of WECS to a specific utility.

This paper will present and compare the WECS utility value analysis methodologies of Aierospace Corp., JBF Scientific Corp., and the Solar Energy Research Institute (SERI). Results of the application of these three methodologies were found for two large utilities. Breakeven values (the amount a utility can pay for: a wind turbine orver it's lifetime and still breakeven economically) were found to be from $\$ 1600$ to $\$ 2400$ per $\mathrm{kW}$ of wind capacity in 1980 dollars. The reasons for variation in the results are discussed.
\end{abstract}

\title{
INTRODUCTION
}

This paper compares methods developed for conducting economic assessments of wind energy conversion systems (WECS) in utility applications. The methods compared were developed under Department of Energy sponsorship by the Solar Energy Research Institute (SERI), the Aerospace Corporation (AERO), and the JBF Scientific Corporation (JBF). The purpose of this comparative analysis is to identify any discrepancies among the methods and corresponding changes that might be required to improve their accuracy.

The general economic assessment methodology is referred to as value analysis. Value is the amount a utility could afford to pay for a wind turbine, based on its performance and the cost of the conventional alternatives that may be displaced if WECS are installed. Because the wind is available intermittently, the utility has minimum control over the level of wind generation at any time. WECS cannot be dispatched at will, and thus, cannot be represented directly in utility planning models like conventional generating units. As a result, special modeling is required to accurately include WECS in the utility planning process.

SERI, Aerospace and JBF all use the same basic approach to value analysis. This approach is illustrated in Fig. 1 and involves simulating the operation of the utility system with and without WECS. In the top leg of the figure, the withoutWECS base case is performed. For a single year, the base-case load forecast 
and generating units are specified; the fuel, operation and maintenance costs are estimated; reliability indices are calculated. Next the operation of the utility system with WECS is performed, as indicated in the lower leg of the figure. This involves first estimating the WECS performance, and then appropriately reducing the base-case utility load data. This WECS modified load curve is then used to again estimate the fuel, operation and maintenance costs, as well as new reliability indices. These before and after WECS results are then compared to yield operations cost savings, as well as savings due to conventional capacity that is no longer needed after the WECS installation. The present value of these savings extrapolated for the lifetime of the WECS is the breakeven value of the wind turbine to the utilit.y.

Although their basic approach is the same, SERI, Aerospace and JBF use different computer models to conduct the analysis in each step outlined above. For details of the respective methodologies, see Percival and Harper (1981), JBF Scientific Corporation (1981), and Aerospace (1981). To determine how these different models affect the value results obtained, all three groups analyzed case studies of WECS installed (1) at the San Gorgonio site in the Southern California Edison (SCE) utility system, and (2) at the Ludington site in the Consumers Power Company (CPC) utility system. As much as possible, all three used the same input data regarding the wind resource, wind turbine characteristics, generating units, load forecasts, fuel costs and fuel cost escalation rates.

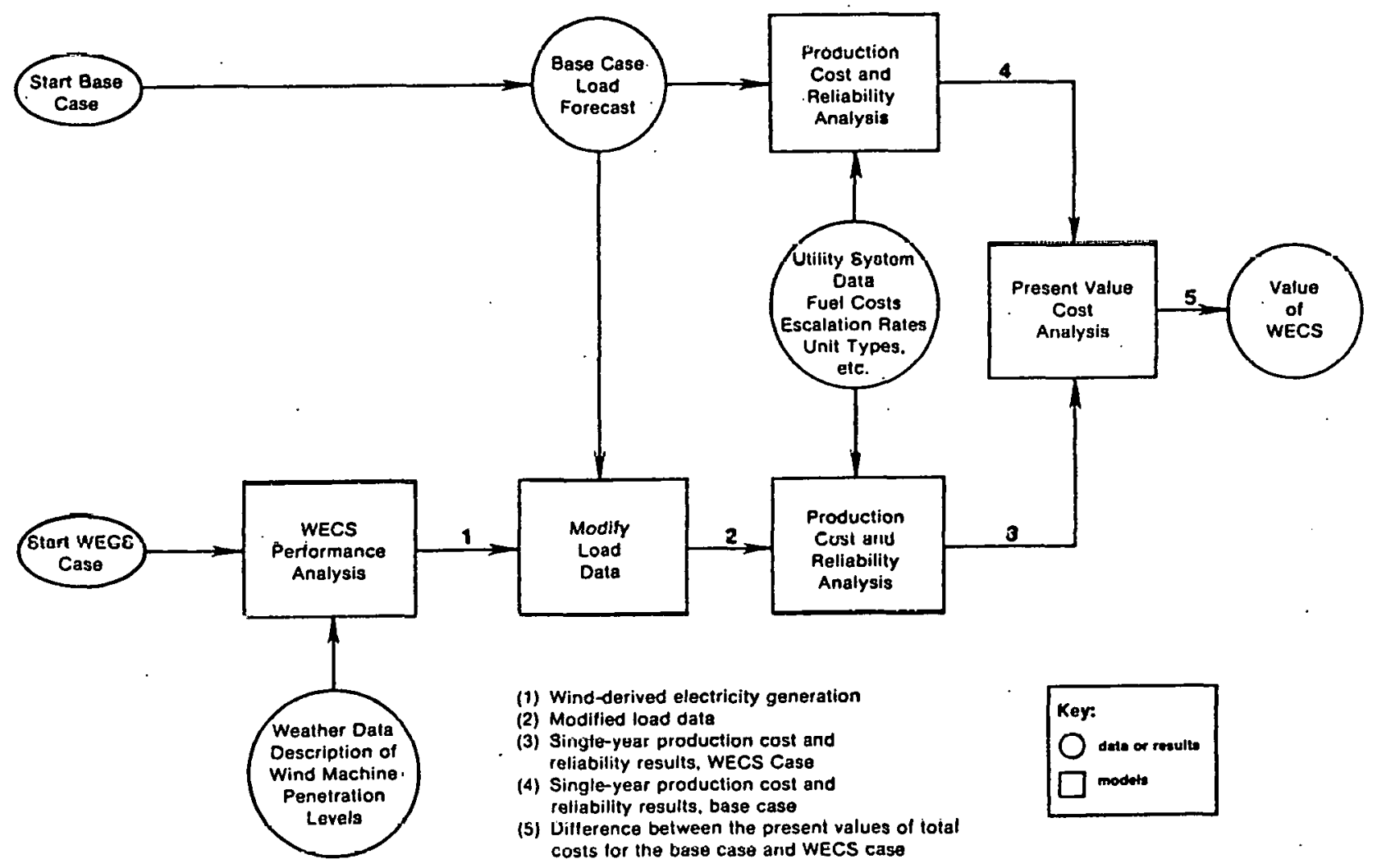

Figure 1. Basic Value Analysis Methodology 
The four methods of value analysis to be compared are: SERI Hourly (SERI-H), SERI Weibull (SERI-W), Aerospace (AERO), and JBF Scientific Corp. (JBF). Following a brief description of the utilities to be modeled, the analysis methods will be compared at each stage of the modeling sequence.

\section{SOUTHERN CALFORNIA EDISON CHARACTERISTICS}

The Southem California Edison (SCE) utility system was the first utility selected as a case study to be analyzed by the three analysis teams. All results discussed in the sections that follow are based on an analysis of a single year (1980) to obtain fuel, operation, and maintenance and capacity displacement. These results were then escalated to the year 2010 to obtain estimates of the present value of savings over the lifetime of the wind turbines. All utility and economic data used in the analysis are data obtained directly from SCE.

Wind resource data are from the San Gorgonio site in California, which as excellent resources for producing electricity using the MOD-2, $2.5 \mathrm{MW}$ wind turbine. SCE is a summer peaking system with the annual peak for 1980 being 12,680 MW. SCE projects the 1985 peak to be $14,600 \mathrm{MW}$, with the $20,000 \mathrm{MW}$ level being reached in 1995. The system is heavily dependent upon oil fired capacity, with $75 \%$ of the capacity being oil in 1380. Future additions of coal and nuclear capacity are projected to decrease oil capacity to about $56 \%$ in 1995 . Projected fuel costs make oil generation a tremendous cost burden relative to other fuels in the future. Like most large utilities, SCE is interconnected with neighboring utilities, the largest being transactions with the Bonneville Power Administration. More detailed input data for the SCE analysis is given in Sullivan (1981). The results for the 5\% penetration scenario (WECS capacity as a percent of peak demand -254 MOD-2's in 1980) will be evaluated in the comparative analysis of the four methodologies.

\section{CONSUMERS POWER COMPANY CHARACTERISTICS}

The second utility selected for common analysis was the Consumers Power Company (CPC). This generating system is operated in close coordination with the Detroit Edison (DE) system, with the two systems being dispatched as a single system to meet their combined load requirements. For this reason, the results presented in ths report are for the combined CPC/DE system. All results discussed in the sections that follow are based on an analysis of the single year 1982. The utility and economic data used in the analysis was obtained directly from the CP planning department.

The CPC/DE system 1982 projected peak demand of 12,750 MW occurs in June. The capacity mix in 1982 is: $50 \%$ coal, $31 \%$ oil, $11 \%$ nuclear, $1 \%$ hydro, $7 \%$ pumped hydro. This ratio is projected to change very slightly over the next 15 years, and the reserve margin is projected to stay at a high 25-40\%. Large transactions occur with Ontario Hydro and American Electric Power. Again, more detailed data used in the analysis is given in Sullivan (1981). Comparison of analysis results will be given primarily for the 1982 case with $5 \%$ wind penetration (637.5 MW).

\section{WIND MODELING}

Relative to many sites, substantial wind resource data are available for the San Gorgonio and Ludington sites. Two minute wind velocity data (instantaneous measurements made every two minutes) were available for 1979 for both sites. To maintain maximum consistency of input data, SERI corrected this year of weather data for missing or bad data and gave an identical set to each of the analysis teams. 
Given the wind resource data; the next step is to estimate electricity generated by the wind turbine. Since the wind data was recorded at a 150 foot above ground level at both sites, identical extrapolation to the MOD-2 hub height of 200 feet was performed by each team using the $1 / 7$ power law. All teams then used the same elevation corrected MOD-2 power curve for determining electrical power output of the wind turbines given the hub height wind speed. Ambient temperature effects upon the power output were identically made by each team. Wind diversity was not considered, thus all wind turbines were assumed to produce the same power at any instant.

The SERI-H and JBF methods each used two minute wind speeds to produce two minute wind powers. These wind powers are then averaged to get hourly wind powers. The hourly averages are later used to create the residual loads needed to calculate production cost and capacity credits. The AERO method uses the same method for creating residual loads to estimate system production costs with WECS. But a probabilistic wind power concept is uoed for extimation of WECS capacity credits, since the AERO capacity credit portion of the analysis is unique. With this concept, a probability distribution of wind power outputs for each hour of a monthly typical day (24 hours characterizes each month) is created. These WECS power distributions are later convolved with available capacity states for the entire utility system to determine the effective load carrying capability of the WECS.

The SERI-W method uses the available two minute wind data to create Weibull wind probability distributions for each hour of a monthly typical day (again, 24 distributions characterizes each month). In the original version of the SERI-W method, the Weibull probability distribution was estimated for all wind velocities measured for particular hours of the day. In the course of the analysis, SERI discovered that this method consistently underestimated wind generation relative to using wind data directly in the performance model. The correct this problem, SERI modified the SERI-W method so that the Weibull distribution is estimated only for wind speeds equal to or higher than the cut-in speed for the turbine being analyzed. This correction improved the estimates of wind generation with the Weibull, with the SERI-W WECS annual capacity factor being $31.7 \%$ versus the other three method's $31.5 \%$ for San Gorgonio. Ludington's annual capacity factor was $31.7 \%$ for the Weibull method, and $31.7 \%$ for the hourly method by SERI-H, JBF, and AERO (production cost).

The above capacity factors include proper treatment of the WECS forced outage rate. If the hourly techniques were used, then the WECS power output is simply derated by multiplying the WECS power by the WECS availability (1-forced outage rate). With the probabalistic Weibull method, the probabilities of power outputs are all multiplied by the availablity, with the forced outagc rutc being added to the probability of zero power output.

\section{LOAD MODIFICATION}

Before modifying the load representation to reflect WECS power, the utility's base case load data must first be modified to take account of both purchase and sales from neighboring utilities, as well as for the existence of hydro capacity. In creating this modified load, care must be taken to insure that both the hydro scheduling and the purchases and sales are represented accurately, i.e., that both the demand and energy. displaced reflect actual operating practices. 
All analysis teams show reasonably good agreement in modeling transactions, but hydro production estimates vary by about $10 \%$ between JBF and AERO. It must be noted that SERI and JBF remove the hydro generation by economically dispatching it, whereas Aerospace subtracts hydro generation from the base case load data before running their production cost model. In theory, there should be little difference between these two approaches if the dispatching logic used in the SERI and JBF computer codes accurately duplicates the hydro scheduling procedure used by AERO. The fact that there are differences in the results suggests that this duplication is not perfect.

\section{LOAD MODIFICATION FOR PRODUCTION COST ANALYSIS}

All of the contractors subtract hourly WECS production from the hourly load data in order to estimate the production cost savings associated with installing WECS. (Production cost savings are savings in fuel, operation and maintenance costs.) SERI and JBF subtract WECS production from the base case load data; AERO modifies the base case load data to account for purchases, sales and hydro production before subtracting WECS production. The procedure for load modification with the SERI-W method involves convolving the WECS capacity probability distribution with the system load to obtain the residual loads and corresponding probabilities. By ordering these residual probability pairs in descending order and properly combining the pairs, the probabilistic nature of the results are preserved. More detail on the SERI-W procedure is given in Percival and Harper (1981).

The results of the load modification for the four methods can be examined in terms of reduced monthly energy (gigawatt-hours) and reduction in monthly peak demand (megawatts). The energy results for all four methods are very close, hith the largest difference being $13.4 \%$ for SCE in the month of September.

The results for the reduction in peak demand differ significantly, as shown in Table 1 for SCE (CPC/DE results show similar variation). These differences are due to several reasons. The SERI-W method is probabilistic and uses all data available to construct one monthly typical day to represent every day of the month for load modification purposes, as previously discussed. In contrast, the other three methods simply use the data available for each hour of each day to modify loads. As is to be expected, the hourly data methods result in a wider range of peak load reductions (from 0 to $298 \mathrm{MW}$ for SCE), reflecting the variation in wind speeds observed for individual hours. The SERI-W method results in a narrower range of peak load reductions (from 2 to $71 \mathrm{MW}$ for SCE), because each typical hour is constructed from 30 hours of observation (where $30=$ the number of days per month).

Among the three hourly methods, the SERI-H and JBF methods produced nearly identical results for SCE peak demand reductions. AERO's results for SCE differ significantly because the peak loads have been adjusted to reflect hydro production and purchases and sales. Thus, AERO's results are not comparable to SERI's and JBF's. Ideally, we would need to have residual load and unit dispatch data for all three methods to compare their results. Unfortunately, these data are not available. 


\section{LOAD MODIFICATION FOR CAPACITY DISPLACEMENT ANALYSIS}

For the purposes of estimating the conventional capacity displaced by WECS, both SERI-W, SERI-H and JBF use the same load modification procedures described for production credit analysis. Aerospace, on the other hand, used their loss-of-load probability model for capacity displacement analysis. In this method, the typical hour probability distributions describing the availability of WECS capacity are convolved with the outage distributions of the conventional units to create the outage capacity probability distribution table. From this table and load data, the probability that there is insufficient capacity to serve the load-which is the loss-of-load probability (LOLP)-is determined, as is the effective load carrying capacity. With this information, the conventional capacity savings attributable to WECS can be inferred.

Tyble 1. Reduction in Peak Demand For the SC:E System After Adjusting for Wind-Derived Generation $^{\mathrm{a}}$

\begin{tabular}{ccccc}
\hline & \multicolumn{4}{c}{ Method } \\
\cline { 2 - 5 } Month & SERI-W & $\begin{array}{c}\text { SERI-H } \\
\text { (megawatts) }\end{array}$ & AERO & JBF \\
\hline 1 & 30 & 0 & 0 & 0 \\
2 & 65 & 0 & 8 & 0 \\
3 & 49 & 160 & 298 & 160 \\
4 & 11 & 143 & 30 & 143 \\
5 & 45 & 3 & 4 & 3 \\
6 & 21 & 250 & 205 & 258 \\
7 & 14 & 0 & 0 & 0 \\
8 & 16 & 215 & 165 & 215 \\
0 & 10 & 5 & 3 & 5 \\
10 & 40 & 21 & 3 & 21 \\
11 & 71 & 8 & 0 & 8 \\
12 & 2 & 10 & 0 & 5 \\
\hline a Results arc for 635 MW of wind turbines (5\% of peak \\
demand). \\
b
\end{tabular}

PRODUCTION CREDTT ANALYSIS

In this section, the methodologies used by the analysis teams to determine the production cost savings attributable to WECS will be described, with emphasis on the differences among the four approaches. In addition, the results obtained from applying the different approaches to the SCE and CPC/DE systems will be presented.

In general, SERI and JBF use a probabilistic production costing technique whereas AERO uses a deterministic approach. Both techniques basically simulate the annual operation of the utility system by economically dispatching 
generating units to meet the load. The probabilistic methods explicitly represent the randomness in the loads as well as the randomness in the availability of the conventional capacity. Further, the loads adjusted for WECS capacity are transformed into probability distributions that describe the probability that the load will exceed a given level during an interval of time such as a week or month. SERI employs the widely used PROMOD code to determine the production credit of WECS on a monthly basis. Similarly, JBF uses the SYSGEN program for production costing.

Aerospace uses a deterministic technique, which models the random failures of the conventional generating units by derating: the capacity of the units by multiplying that capacity be the unit availability. All three production cost models require basically the same data, and all models produce the same basic production statistics, except that AERO's deterministic technique does not estimated system reliability indices, as does PROMOD and SYSGEN.

\section{PRODUCTION COST RESULTS FOR SCE}

For the SCE 1980 system with a $5 \%$ penetration of MOD-2s, the reduction in energy to be served by the conventional units and the changes in operating costs estimated by the three contractors are in reasonable agreement. The total cost savings due to the WECS varied by only $2.6 \%$ across all the methods. About $94 \%$ of the total savings are from displaced oil. The largest variation is in the results of distillate fuel savings, which varied in cost. by $85 \%$ among the methods. Since this fuel is used by peaking units, it is reasonable to expect some variability in their values due to the difficulty of to simulating accurately those few hours when peaking units are required. Furthermore, as discussed earlier, differences in the scheduling of purchases, sales, and hydro production will influence peak period results quite substantially. Finally, since the contractors, especially Aerospace, use quite different production cost models, some variability in results should be expected. Complete listings of energy and cost savings due to WECS are displayed in Sullivan, Flaim, and Percival (1981).

\section{PRODUCTION COST RESULTS FOR CPC/DE}

The reduction in energy to be served by the conventional units and the changes in operating costs estimated by the analysis teams are shown in Table 2. These results are for the 5\% penetration of WECS (MOD-2s), based on the year 1982 .

It is obvious that there are significant differents in the energy results, even though differences in the total savings are small $(6.4 \%)$. The distribution of these total savings among fuel types indicates significant modeling differences. Part of the variation may be attributable to the different approaches to modeling purchase agreements and hydro production, as well as the inherent differences between deterministic and probabilistic production cost models. The major source of variation, however, is probably due to the different approaches used to model pumped hydro generation. The CPC/DE system has a $1248 \mathrm{MW}$ pumped hydro plant in 1982. The production cost model used by SERI (PROMOD) uses a set of three load duration curves per month (peak period, weekday off-peak period, and remaining weekend period) to accurately simulate pond charging and discharging. The 1982 SERI base case pumped storage capacity factor of $16.3 \%$ is not far from the historical capacity factor of $17 \%$. The JBF model (SYSGEN) uses a single load duration curve per month and results 
in a 1982 pumped hydro capacity factor of $29.8 \%$. The pumped hydro portion of the AERO model was not functioning at the time of this study so Aerospace had to ignore the pumped hydro plant entirely.

Table 2. $\quad$ Estimated Energy and Cost Savings by Fuel Type for the CPC/DE System in 1982

\begin{tabular}{|c|c|c|c|c|c|}
\hline & \multicolumn{4}{|c|}{ Method } & \multirow{2}{*}{$\begin{array}{l}\text { Percent } \\
\text { Variation }\end{array}$} \\
\hline & SERI-W & SERI-H & AERO & JBF & \\
\hline \multicolumn{6}{|c|}{ (gigawatt hours) } \\
\hline \multicolumn{6}{|l|}{ Energy Savings } \\
\hline Gas-Distillate & 56 & $5 \dot{9}$ & 175 & 112 & 212.5 \\
\hline Oil & 390 & 404 & 673 & 692 & 77.4 \\
\hline Coal & 854 & 713 & 640 & 581 & 47.0 \\
\hline Nuclear & 3 & 2 & 0 & 0 & \\
\hline Purchases & 474 & 609 & 301 & 366 & 102.3 \\
\hline Emergency Energy & 11 & 9 & 0 & 0 & \\
\hline Pumped Hydro & 65 & 72 & $\mathrm{~d}$ & 5 & 1340.0 \\
\hline Total & 1,853 & 1,868 & 1,789 & 1,756 & 6.4 \\
\hline \multicolumn{6}{|c|}{ (thousands of dollars) } \\
\hline \multicolumn{6}{|l|}{ Cost Savings } \\
\hline Gas-Distillate & 3,494 & 3,640 & 10,618 & 6,800 & 203.9 \\
\hline Oil & 27,855 & 28,918 & 46,608 & 50,700 & 82.0 \\
\hline Coal & 22,564 & 19,733 & 15,767 & 16,200 & 43.1 \\
\hline Nuclear & 25 & 15 & 0 & 0 & \\
\hline Purchases & 14,283 & 18,353 & 9,067 & 11,100 & 102.4 \\
\hline Emergency Energy & 1,537 & 1,531 & 0 & 0 & \\
\hline O\&M & 3,277 & 3,025 & 3,487 & 2,500 & 39.5 \\
\hline Total & 73,035 & 75,215 & 85,547 & 87,300 & 19.5 \\
\hline
\end{tabular}

apercent variation is the variation between the smallest and largest values in the row. The differences between the percent variations for the energy results and the percent variations for the cost results is probably due to one or more of the following: (1) different heat rates for different units estimated to be operating at any point in time, (2) different dispatch logic for transactions and hydro production, (3) differences in assumed spinning reserve policies or (1) differences in pumper hydro modeling or lack thereof.

\section{CAPACITY DISPLACEMENT ANALYSIS}

To estimate the capacity credit associated with wind turbines, it is necessary to perform a series of reliability analyses with and without WECS. Specifically, the system into which wind turbines are to be integrated must be defined and its reliability evaluated. Adding WECS to a system might increase the system's reliability, making it possible to remove some of the conventional capacity to return the system reliability to its original level. 
To determine the capacity displacement of WECS, SERI and JBF used their probabilistic production cost models to calculate the reliability of the SCE system, with and without WECS. By equalizing the with wind and without wind loss of load probability (LOLP-probability of the load exceeding available capacity) estimates, the effective load carrying capability of the wind turbines was estimated. Aerospace applied a similar procedure, but used their separate Loss-ofLoad Probability Program (LOLPP). Unlike the method used in probabilistic production cost. models used by SERI and JBF, LOLPP calculates loss-of-load probabilities for every hour and accumulates the values to obtain the annual LOLP. As perviously mentioned, distributions of WECS power outputs are convolved in LOLPP with the probability distribution of system capacity levels. In concept, all three methodologies are similar. But because of computational differences, they produce measures of LOLP that are difficult to compare.

\section{CAPACITY DISPLACEMENT RESULTS FOR SCE}

The annual LOLPs for SCE are shown in Table 3. Clearly, these results are not at all comparable, yet they lead to similar estimates of effective load carrying capability (ELCC). ELCC is the amount of firm capacity (capacity with zero scheduled or unscheduled outages) that could be displaced by WECS, with no degradation in system reliability. Although the four estimates of ELCC are more similar than the LOLP results, the estimates range from 126 to $177.9 \mathrm{MW}-$ -a $4.1 \%$ variation.

We suspect that some of the variation in ELCC might be due to differences in how transactions and hydro production are modeled. In addition, it is to be expected that differences in reliability impacts would be greater than for energy impacts, because the former are most sensitive to the peak hours in the year, while the later are based on all hours in the year. However, the dominating discrepancy in actual values of LOLP between methods could not be satisfactorily explained, even with considerable discussion among teams. While utility modelling differences can explain some of the LOLP differences, the acutal reliability calculations in each computer are suspect. The first possibility was checked as carefully as possible, while the second possibility was impossible to check due to the proprietary nature of the computer models PROMOD and LOLPP.

Given the reliability impacts of WECS, a generation expansion model could have been used to determine the optimal changes in the timing and type of generating unit additions. However, using a generation expansion model was beyond the scope of this endeavor. Instead, the three contractors had to use their best judgment to determine which types of capacity would be removed from the base-case expansion plan provided by SCE.

Differences in the amount of capacity displaced are attributable to different estimates of the ELCC of WECS. All contractors assumed that oil capacity would be displaced, but the timing of the displacement varied by five years.

\section{CAPACITY DISPLACEMENT RESULTS FOR CPC/DE}

The capacity credit results for $\mathrm{CPC} / \mathrm{DE}$ are also listed in Table 3. Compared to the SCE case, the CPC/DE system IOLPs had a lower variation among the three agencies, but the resulting ELCC variation was almost the same (40\%). As with 
SCE, no firm explanation can be given for absolute differences in LOLP numbers between methods. However, the order of these ELCC estimates is correlated with each agency's estimated capacity factor for the pumped hydro plant. AERO's estimated capacity factor was zero since did not include the plant, SERI's estimate was $16.3 \%$ and JBF's $29.8 \%$. The correlation between ELCC estimates and pumped hydro capacity factors also existed in the results for the other years studied (1985 and 1995).

Note on the same table that these assumed conventional capacity changes due to WECS additions deviate even more than the ELCC estimates. For conveninece, SERI and AERO assumed that the displaced capacity would be a single hypothetical 1982 unit, with no planned maintenance and an $8 \%$ forced outage rate. In contrast, JBF assumed that three existing units would be eliminated. Since actual units come indiscrete sizes, and have planned maintenunce and higher forced outage rates (up to 34\%), more capacity was displaced in the JBF methon.

Table 3 Capacity Credit Results

\begin{tabular}{|c|c|c|c|c|}
\hline & SERI-W & SERI-H & AERO & JBE \\
\hline \multicolumn{5}{|l|}{ SCE-635 MW Wind-1980 } \\
\hline \multicolumn{5}{|l|}{ Base Case Reliability } \\
\hline (loss of load hours) & 61.1 & 61.1 & 0.189 & 9.86 \\
\hline \multicolumn{5}{|l|}{ WECS Case Reliability } \\
\hline (loss of load hours) & 47.4 & 48.9 & 0.111 & 8.97 \\
\hline ELCC in $M W$ & 177.9 & 161.5 & 130.0 & 126.0 \\
\hline ELCC as \% of WECS Capacity & 28.0 & 25.4 & 20.5 & 19.8 \\
\hline $\begin{array}{l}\text { Displacement due to WECS } \\
\text { (MW oil capacity) }\end{array}$ & $\begin{array}{l}178 . \\
\text { in } 1985\end{array}$ & $\begin{array}{l}164 . \\
\text { in } 1985\end{array}$ & $\begin{array}{l}135 . \\
\text { in } 1980\end{array}$ & $\begin{array}{l}126 . \\
\text { in } 1980\end{array}$ \\
\hline \multirow{2}{*}{\multicolumn{5}{|c|}{$\begin{array}{l}\text { CPC/DE - 63\%.5 MW Wind-1982 } \\
\text { Base Case Reliability }\end{array}$}} \\
\hline & & & & \\
\hline (loss of load hours) & 81.9 & 81.9 & 169.3 & 92.6 \\
\hline \multicolumn{5}{|l|}{ WECS Cas Reliability } \\
\hline (loss of load hours) & 64.4 & 64.1 & 129.4 & 59.5 \\
\hline $\mathrm{ELCC}$ in $\mathrm{MW}$ & 176.0 & 184.0 & 166.0 & 232.0 \\
\hline ELCC as $\%$ of WECS Capacity & 27.6 & 28.9 & 28.0 & 36.4 \\
\hline \multicolumn{5}{|l|}{ Displacement due to WECS } \\
\hline (MW oil capacity in 1982) & 183 & 187 & 183 & 382 \\
\hline
\end{tabular}

BREAKEVEN COST ANALYSIS

This section discusses the final stage of the analysis, where the production cost savings and capacity displacement are translated into a breakeven cost for the wind turbines. For convenience, the production and capacity credit results will be presented scparately. However, once the two are determined, they can be added together to obtain a total credit associated with installing WECS.

Because the results that were reported in the preceding sections were based on an analysis of the SCE system for a single year, the cost results must be escalated and then discounted to estimate the present value of savings over the life- 
time of the WECS. Since the three contractors use the same approach for the present value calculations and the same input assumptions, a detailed discussion of their equations is unnecessary. (See Percival and Harper (1981), Aerospace (1981) and JBF (1981).

The present value of operating cost and capacity credits associated with each year and penetration of MOD-2s in the SCE system are presented in Table 4. The production cost results are quite close, with a maximum variation of $5.3 \%$ in 1995. The estimated capacity credits in the 1980 case vary by $20 \%$, which is less than the $41 \%$ variation in estimated ELCC. The variation declined because SERI-which had the highest estimates of ELCC-assumed that conventional capacity would be displaced five years later than the other contractors assumed. Thus, SERIs higher estimate of ELCC was offset by its lower present value of capacity savings. The total breakeven costs for 1980 are also quite close because the larger production cost savings dominate the smaller capacity savings.

The results for the combined $\mathrm{CPC} / \mathrm{DE}$ system are presented in Table 5. The exact reason for the year-to-year variation in production cost savings differences is not known, however, it is likely that the year-to-year variability across methods is due to the following: (1) differences among the methods' treatment of the pumped hydro plant, and (2) the changing reserve margin and mix of generating units for the CPC/DE system. The capacity savings reported by SERI and AERO were nearly identical. The JBF capacity savings were appreciably higher, due to their higher ELCC estimates and their assumption that existing capacity could be sold for the WECS capacity credit.

Table 4. Estimated WECS Production and Capacity for the SCE System (1980 dollars per $\mathrm{kW}$ )

\begin{tabular}{|c|c|c|c|c|c|c|c|}
\hline \multirow[b]{2}{*}{ Year } & \multirow[b]{2}{*}{$\begin{array}{c}\text { Percent } \\
\text { Penetration }^{\mathrm{a}}\end{array}$} & \multirow[b]{2}{*}{$\begin{array}{l}\text { Source of } \\
\text { Savings }\end{array}$} & \multicolumn{4}{|c|}{ Method } & \multirow[b]{2}{*}{$\underset{\text { Variation }}{\text { Percent }}$} \\
\hline & & & SERI-W ${ }^{b}$ & SERI-HC & AERO & JBF & \\
\hline 1980 & 5.0 & $\begin{array}{l}\text { Production } \\
\text { Capacity } \\
\text { Total }\end{array}$ & $\begin{array}{r}1554 \\
78 \\
1632\end{array}$ & $\begin{array}{r}1521 \\
72 \\
1593\end{array}$ & $\begin{array}{r}1559 \\
70 \\
1629\end{array}$ & $\begin{array}{r}1557 \\
65 \\
1622\end{array}$ & $\begin{array}{r}2.5 \\
20.0 \\
2.4\end{array}$ \\
\hline 1995 & 5.0 & $\begin{array}{l}\text { Production } \\
\text { Capacity } \\
\text { Total }\end{array}$ & $\begin{array}{r}1317 \\
91 \\
1408\end{array}$ & & $\begin{array}{r}1308 \\
50 \\
1358\end{array}$ & $\begin{array}{r}1251 \\
118 \\
1369\end{array}$ & $\begin{array}{r}5.3 \\
136.0 \\
3.7\end{array}$ \\
\hline
\end{tabular}

a Percent penetration is the rated capacity of the wind machines, expressed as a percentage of peak demand.

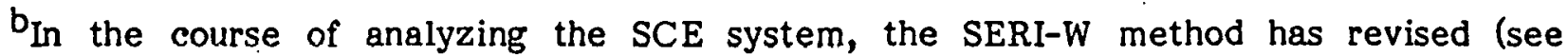
Sec. 4.2). The 1980 5\% penetration case was recalculated using the revised SERI-W method. The results reported for the 1995 case are approximate corrections to the original SERI-W results. 1985 was not studied.

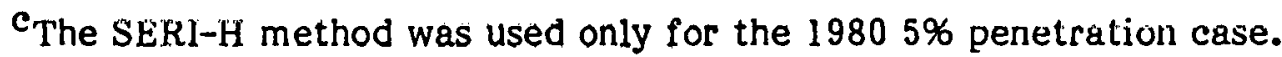

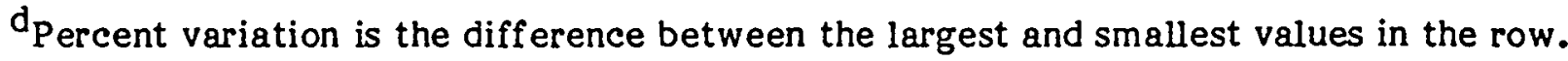


Table 5. $\quad$ Estimated WECS Production and Capacity Credits for the CPC/DE System (1980 dollars per $\mathrm{kW}$ )

\begin{tabular}{|c|c|c|c|c|c|c|c|}
\hline \multirow{2}{*}{\multicolumn{2}{|c|}{ Year $_{\text {Penetration }}^{\text {Percent }}$}} & \multirow[b]{2}{*}{$\begin{array}{l}\text { Source of } \\
\text { Savings }\end{array}$} & \multicolumn{4}{|c|}{ Method } & \multirow[b]{2}{*}{$\begin{array}{l}\text { Percent } \\
\text { Variation }\end{array}$} \\
\hline & & & SERI-W & SERI-H & AERO & $\mathrm{JBF}$ & \\
\hline 1982 & 5.0 & $\begin{array}{l}\text { Production } \\
\text { Capacity } \\
\text { Total }\end{array}$ & $\begin{array}{r}1778 \\
66 \\
1844\end{array}$ & $\begin{array}{r}1845 \\
65 \\
1910\end{array}$ & $\begin{array}{r}2180 \\
65 \\
2245\end{array}$ & $\begin{array}{r}2270 \\
198 \\
2468\end{array}$ & $\begin{array}{r}27.7 \\
204.6 \\
33.8\end{array}$ \\
\hline 1985 & 5.0 & $\begin{array}{l}\text { Production } \\
\text { Capaicity } \\
\text { Total }\end{array}$ & $\begin{array}{r}1712 \\
62 \\
1774\end{array}$ & $\begin{array}{r}1716 \\
62 \\
1778\end{array}$ & $\begin{array}{r}1777 \\
62 \\
1839\end{array}$ & $\begin{array}{r}1691 \\
144 \\
1835\end{array}$ & $\begin{array}{r}5.1 \\
132.2 \\
3.7\end{array}$ \\
\hline 1995 & 5.0 & $\begin{array}{l}\text { Production } \\
\text { Capacity } \\
\text { Total }\end{array}$ & $\begin{array}{r}4475 \\
65 \\
4540\end{array}$ & $\begin{array}{r}4597 \\
64 \\
4661\end{array}$ & $\begin{array}{r}4033 \\
66 \\
4099\end{array}$ & $\begin{array}{r}4566 \\
189 \\
4755\end{array}$ & $\begin{array}{r}14.0 \\
195.3 \\
16.0\end{array}$ \\
\hline
\end{tabular}

\section{SUMMARY AND CONCLUSIONS}

The four methodologies developed by SERI, the Aerospace Corporation, and the JBF Scientific Corporation for estimating the value of wind turbines were applied to a case studies for the Southern California Edison system and the combined Consumers Power and Detroit Edison system. To the maximum extent practicable, identical input assumptions were used by the three contractors. The results in different phases of the analysis were compared in an attempt to identify any major discrepancies among the methods.

The wind modeling section of the analysis contained no significant differences between methods, due to common wind data handling, similar WECS performance models, and the accuracy of the Weibull curve fitting process. The authors recommend significant effort in obtaining realistic wind data and performing accurate WECS modeling in order to obtain meaningful value results. Since wind data normally available is not two-minute, but hourly at best, it is recommended that multi-year wind data be used with probabilistic techniques for both operating and capacity savings calculations.

The load modification procedures produced very similar results in reducing monthly energies, but varied considerably in the less important demand considerations due to methodological differences.

Production cost results are in good agreement for SCE, but vary somewhat for CPC/DE primarily due to different approaches in modeling the large pumped hydro unit.

Capacity credit results were considerably different for all four methods on each utility system due to different demand modification, reliability input variations, and perhaps, the calculation procedures in the models themselves. Reconciling these significant differences would require detailed comparisons beyond the scope of this study. 
A breakeven value of about $\$ 1620 / \mathrm{kw}$ for $635 \mathrm{MW}$ of MOD-2's in the $1980 \mathrm{SCE}$ system was obtained within $2.5 \%$ of each other by all four methods. Production savings made up roughly $90 \%$ of this value, with capacity credits making up the remainder. The value for $637.5 \mathrm{MW}$ of $\mathrm{MOD}-2$ 's in the $1982 \mathrm{CPC} / \mathrm{DE}$ system was found to be from $\$ 1850-2470 / \mathrm{kw}$ by the analysis teams. If present value lifetime cost estimates of the MOD-2 are below this breakeven value, then on economic grounds the utility should further consider WECS in their generation plan.

\section{REFERENCES}

Aerospace Corporation. 1981. Electric Utility Value Analysis Methodology for Wind Energy Conversion Systems. SERI/TR-98336-1.. Golden, CO: solar Energy Research Institute.

JBF Scientific Corporation. 1981. Methodology for Determining the Value of Wind Energy Conversion Systems (WECS) for Specific Utility Systems. SERI/TR-98336-2. Golden, CO: Solar Energy Research Institute.

Percival, David; Harper, James. 1981 (Feb). Electric Utility Value Determination for Wind Energy, Volume I: A Methodology. SERI/TR-732-604. Golden, CO: Solar Energy Research Institute.

Sullivan, R. L.; Flaim, Theresa; Percival, David. 1981 (Sep). WECS Value Analysis: A Comparative Assessment of Four Methods. Golden, CO: Solar Energy Research Institute. 